\title{
THE DETERMINATION OF DIKARYOTIC GROWTH RATE IN THE BASIDIOMYCETE SCHIZOPHYLLUM COMMUNE: A BIOMETRICAL ANALYSIS
}

\author{
G. SIMCHEN* and J. L. JINKS \\ A.R.C. Unit of Biometrical Genetics, Department of Genetics, \\ University of Birminghom
}

Received 7.v.64

\section{INTRODUCTION}

THE aim of this paper is twofold: to demonstrate the suitability of fungi for studies in biometrical genetics, and to introduce biometrical methods to fungal genetics and mycology as a tool for investigating a number of important problems.

By studying the genetic control of continuous variation in fungi we have the possibility of (i) exploring further and hence clarifying such important concepts as dominance and non-allelic interaction, (ii) comparing the behaviour of genes at different stages in the fungus' life cycle (dikaryons vs. monokaryons) and (iii) making possible an analysis of the action of genes which control continuous variation, at the physiological and biochemical levels. Additional advantages of using fungi for biometrical analyses are their short life cycles, the ease of handling in large numbers and the strict control which is possible of their environmental conditions. Furthermore, formal genetical analyses of several species of fungi such as Neurospora crassa, Saccharomyces cerevisiae, Aspergillus nidulans and Schizophyllum commune are well advanced, as are also the techniques for genetical investigations.

The higher Basidiomycetes, from the group Hymenomycetes, have been chosen as the subjects of the biometrical investigation for two main reasons: first, the stability of the two principal stages in their life cycles, the monokaryotic and dikaryotic, which can be distinguished easily by the presence of clamp-connections in dikaryons; and second, the availability of discrete wild populations of these organisms and hence the possibility of looking for differences between them and relating these differences to the selection pressures operating within the populations.

The present paper deals with the analysis of growth rate of dikaryons of Schizophyllum commune. Experiments were designed to give answers to two problems:-

I. The magnitude of the heritable and environmental components of variation of this character.

2. The genetic relation between the control of growth rate in the dikaryotic and monokaryotic stages of the life cycle.

* Kindly supported by the Rosalind Franklin Grant from the Friends of the Hebrew University of Jerusalem, 237 Baker Street, London, N.W.1, to whom the author is grateful. $2 \mathrm{~s}$ 


\section{MATERIALS AND METHODS}

Schizophyllum commune is an heterothalic basidiomycete, in which mating is controlled by two incompatibility factors, A and B. The bifactorial, or tetrapolar, incompatibility system is described in detail by Raper (1953) and by Raper and Miles (1958), and only the briefest account will be given here. Formation of a dikaryon is possible only by mating two monokaryons which carry different alleles at both the $\mathrm{A}$ and the $\mathrm{B}$ loci: $\mathrm{A}^{1} \mathrm{~B}^{1} \times \mathrm{A}^{2} \mathrm{~B}^{2} \rightarrow\left(\mathrm{A}^{1} \mathrm{~B}^{1}+\mathrm{A}^{2} \mathrm{~B}^{2}\right)$ (following the notation used by most Schizophyllum geneticists). In certain conditions, the dikaryon forms

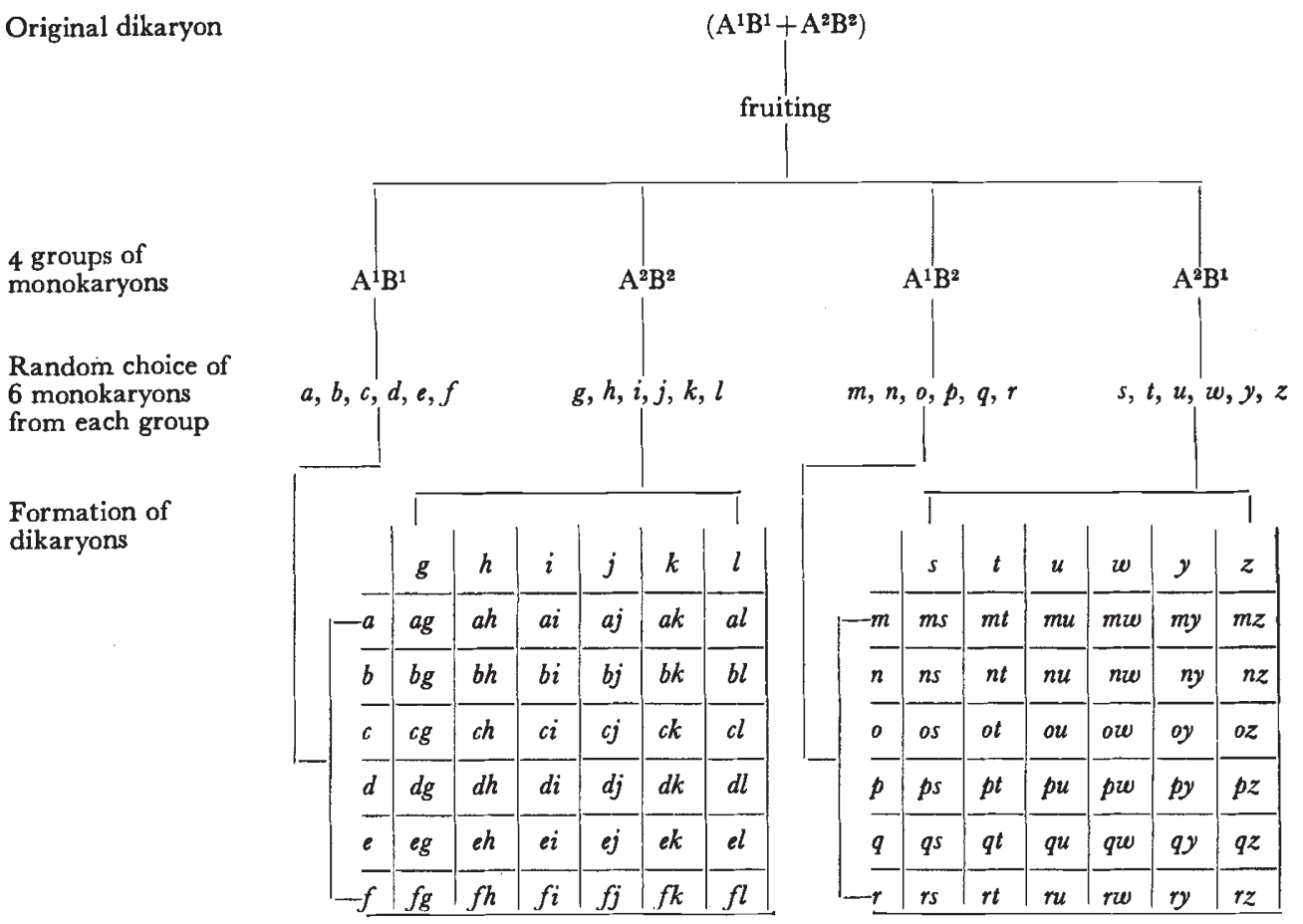

FIG. 1.-The design of the experiments.

fruiting bodies in which nuclear fusion and meiosis occur, followed by the production of basidiospores. The basidiospores germinate to give monokaryons of four incompatibility groups $\left(\mathrm{A}^{1} \mathrm{~B}^{1}+\mathrm{A}^{2} \mathrm{~B}^{2}\right) \rightarrow \mathrm{A}^{1} \mathrm{~B}^{1}, \mathrm{~A}^{1} \mathrm{~B}^{2}, \mathrm{~A}^{2} \mathrm{~B}^{1}, \mathrm{~A}^{2} \mathrm{~B}^{2}$, by independent reassortment, which give new dikaryons only in two combinations: $A^{1} B^{1} \times A^{2} B^{2}$ and $\mathrm{A}^{1} \mathrm{~B}^{2} \times \mathrm{A}^{2} \mathrm{~B}^{1}$.

Two dikaryons were isolated from fruiting bodies recently collected in England: No. I-collected by Dr N. Montgomery, Botany Department, The University of Birmingham, at the beginning of November 1963 , near Mickleham, Surrey; and No. 2-collested by Dr J. Shack, Erdington, Birmingham 24, at the end of November 1963, near Princes Risborough, Buckinghamshire.

The two dikaryons were fruited on plates with SF medium (see later) and monokaryotic progeny were obtained by germinating samples of basidiospores: 40 progeny were obtained from dikaryon No. I and 65 progeny from No. 2. For each dikaryon, the incompatibility reactions of its progeny were determined by mating each monokaryon to selected representatives of each of the four incompatibility 
groups. This operation was carried on SC plates (see later). Six progeny were chosen at random from each of the four groups of monokaryons, and all possible matings were made between them (on SC plates as well). This design is summarised in fig. I.

Three days after making the matings, innocula were transferred to growth tubes to determine the growth rates of the dikaryons. The growth tubes used in these experiments are about $12 \mathrm{~mm}$. in diameter and $15 \mathrm{~cm}$. long, and contain $6 \mathrm{ml}$. of MT medium (a modification of the tubes used by Ryan, Beadle and Tatum, 1943). The tubes containing the inocula were incubated at $25^{\circ} \mathrm{C}$. and the front of the mycelial growth was marked after three days. Ten days later, measurements of the total length of growth from the first mark were recorded.

The two parental dikaryons, with their monokaryotic and dikaryotic descendants, were grown in two separate experiments, each containing four blocks. Each block contained 97 randomised growth tubes, that is one tube each of the original dikaryon, the 24 monokaryons, and the 72 dikaryons, and was confined to a single shelf in the incubator. Each experiment thus consisted of 388 tubes in all.

The media used were:

SC (after Raper and Miles, 1958): $20 \cdot 0 \mathrm{gm}$. dextrose, $20 \cdot 0 \mathrm{gm}$. peptone, $0 \cdot 46 \mathrm{gm}$. $\mathrm{KH}_{2} \mathrm{PO}_{4}, \mathrm{I} \cdot 0 \mathrm{gm} . \mathrm{K}_{2} \mathrm{HPO}_{4}, 0 \cdot 5 \mathrm{gm}$. $\mathrm{MgSO}_{4}$, and $20 \cdot 0 \mathrm{gm}$. New Zealand agar per I litre distilled water.

$\mathrm{SF}: \mathrm{SC}$ medium $+2 \cdot 0 \mathrm{gm}$. yeast extract.

MT: $20^{\circ} \circ \mathrm{gm}$. malt extract, and $20^{\circ} \mathrm{ogm}$. New Zealand agar per I litre distilled water.

\section{RESULTS}

The results of the experiment with dikaryon No. I are summarised in tables 1 and 2, and that with dikaryon No. 2 in tables 3 and 4 . The

TABLE I

\begin{tabular}{|c|c|c|c|c|c|c|c|}
\hline & & $\underset{295}{g}$ & $\begin{array}{c}h \\
3^{H} I^{*}\end{array}$ & $\begin{array}{c}i \\
34^{\circ}\end{array}$ & $\underset{276}{j}$ & $\begin{array}{c}k \\
287\end{array}$ & $\underset{3^{1} 6}{l}$ \\
\hline$a$ & 280 & 291 & 305 & 304 & 292 & 308 & $295^{*}$ \\
\hline & 275 & 299 & $3^{18} 8$ & 305 & 290 & 278 & 271 \\
\hline & 274 & 294 & 308 & 309 & 303 & 305 & 282 \\
\hline$d$ & 296 & $\begin{array}{l}314 \\
\end{array}$ & 339 & 326 & $323^{*}$ & 325 & $3^{1} 3$ \\
\hline & 301 & 319 & 329 & $3^{11}$ & 303 & 298 & 304 \\
\hline & 288 & 308 & $3^{10}$ & $3^{12}$ & 289 & 301 & $28 \mathrm{I}$ \\
\hline
\end{tabular}

TABLE 2

\begin{tabular}{|cc|c|c|c|c|c|c|}
\hline & & $s$ & $t$ & $u$ & $w$ & $y$ & $z$ \\
& & 279 & 255 & 279 & 268 & 292 & 266 \\
\hline & & & & & & & \\
\hline$m$ & $25 I$ & 260 & 265 & 289 & 280 & 285 & 306 \\
$n$ & $30 I$ & $3 I I$ & 297 & 295 & 296 & $302^{*}$ & 298 \\
$o$ & 268 & 285 & 285 & $3 I I$ & 312 & 307 & $320^{*}$ \\
$p$ & 272 & $29 I$ & 297 & 302 & 299 & $28 \mathrm{I}$ & 307 \\
$q$ & 279 & 290 & 287 & 295 & 299 & 290 & 308 \\
$r$ & 287 & 277 & 308 & 300 & $298 *$ & 302 & 315 \\
\hline
\end{tabular}

Ten days growth (in mm.) of monokaryons (in italics) and resulting dikaryons-descendants of dikaryon No. I 
values in these tables are the sums (in $\mathrm{mm}$.) of four replicates. In a few cases, marked by ${ }^{*}$, only three replicates were obtained, and the

TABLE 3

\begin{tabular}{|c|c|c|c|c|c|c|c|}
\hline & & $\begin{array}{c}g \\
33^{\circ}\end{array}$ & $\begin{array}{c}h \\
315\end{array}$ & $\begin{array}{c}i \\
308\end{array}$ & $\underset{3^{23}}{j}$ & $\begin{array}{c}k \\
3^{O O I}\end{array}$ & $\begin{array}{c}l \\
308\end{array}$ \\
\hline 0 & $3 I O$ & $3^{84}$ & 333 & $3^{65}$ & $34^{8}$ & 378 & $35^{8}$ \\
\hline 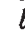 & 317 & 355 & 355 & 350 & $3^{8} 2$ & 352 & 379 \\
\hline & 305 & 374 & 320 & $33^{\circ}$ & $34^{8}$ & $34^{I}$ & 333 \\
\hline & 375 & $39^{\mathrm{I}}$ & $397^{*}$ & 360 & $4^{21}$ & 366 & 398 \\
\hline & $29 I$ & $35^{\circ}$ & 329 & 328 & 333 & 346 & $33^{6}$ \\
\hline & 346 & 372 & $33^{8}$ & 376 & 345 & 366 & $35^{\circ}$ \\
\hline
\end{tabular}

TABLE 4

\begin{tabular}{|cc|c|c|c|c|c|c|}
\hline & & $s$ & $t$ & $u$ & $w$ & $y$ & $z$ \\
& & 279 & 319 & 303 & 256 & 315 & 293 \\
\cline { 5 - 7 } & & & & & & \\
\cline { 1 - 5 }$m$ & 365 & 371 & 388 & 355 & 357 & 389 & $377^{*}$ \\
$n$ & 292 & 286 & 299 & 298 & 309 & 331 & 309 \\
0 & 293 & 298 & 297 & 291 & 305 & 334 & 305 \\
$p$ & 315 & 324 & 329 & 316 & 296 & 362 & 321 \\
$q$ & $34 I$ & 350 & 360 & 355 & 337 & 358 & 343 \\
$r$ & 304 & 325 & 342 & 333 & 306 & 369 & 327 \\
\hline
\end{tabular}

Ten days growth (in mm.) of monokaryons (in italics) and resulting dikaryons-descendants of dikaryon No. 2

missing values were replaced by estimates which minimise the blocks interactions.

A graphic representation of these results is given in figs. 2 and 3 , in the form of frequency distribution for monokaryons and dikaryons.

\section{GROWTH RATE OF DIKARYONS AND THE COMPONENTS OF ITS VARIATION}

Figs. 2 and 3 show that the distribution of growth rates of the dikaryons is continuous, suggesting the heritable variation in this character is under polygenic control.

The components of variation of dikaryotic growth rate were estimated by an analysis of variance of all the data concerned with growth rate of the dikaryotic combinations, i.e. the detailed data summed in the inner $6 \times 6$ squares of tables $\mathrm{I}, 2,3$ and 4 .

From this analysis, estimates of the different components of variation are readily obtainable from the mean squares by a method which has been described in detail by Comstock and Robinson (1948; 1952), although these authors have not discussed a situation like the present one, in which the crosses are between haploid and hence homozygous lines. 


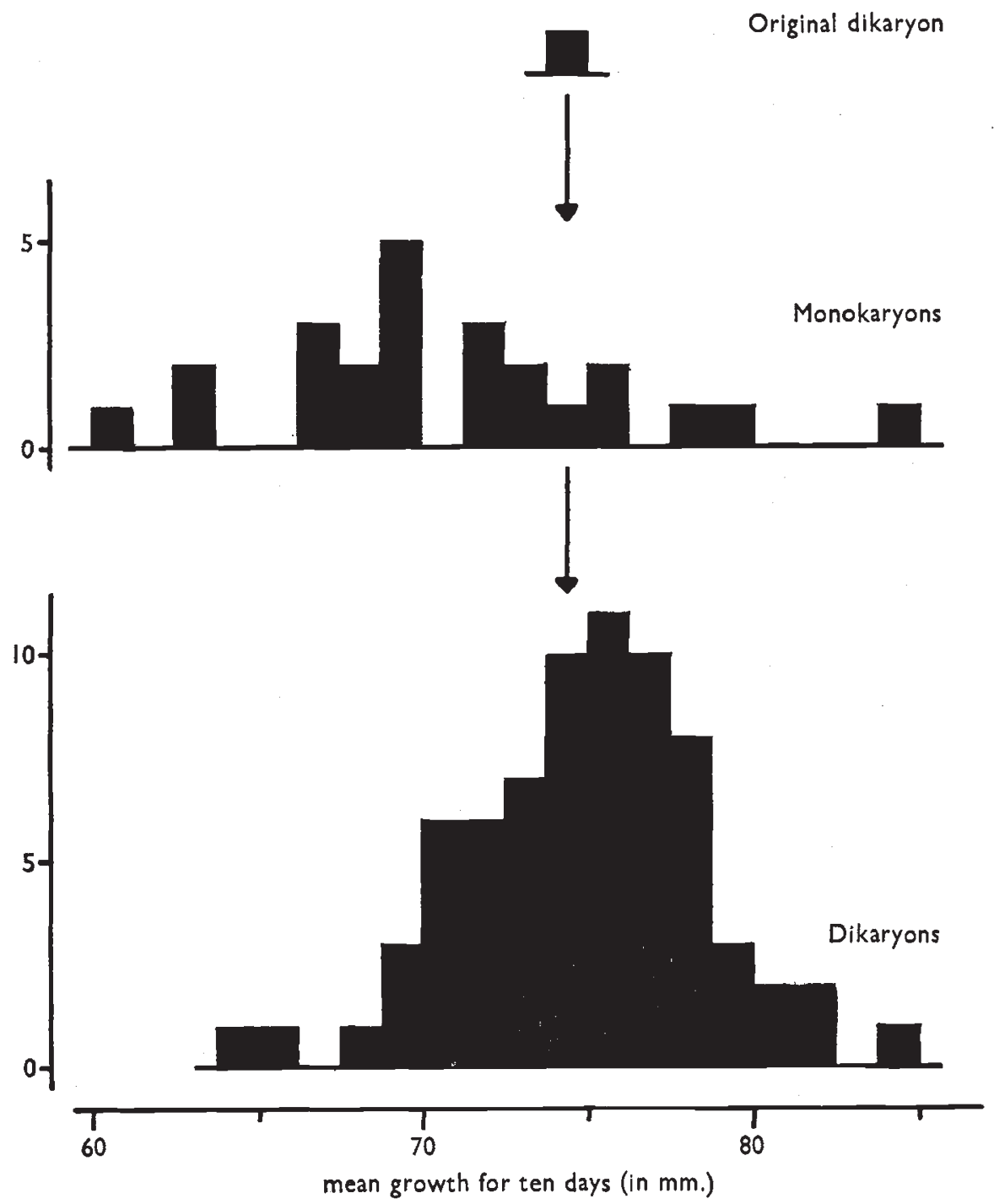

FIG. 2.-A frequency diagram showing mean growth rates for ten days, of dikaryon No. I and its descendants. 


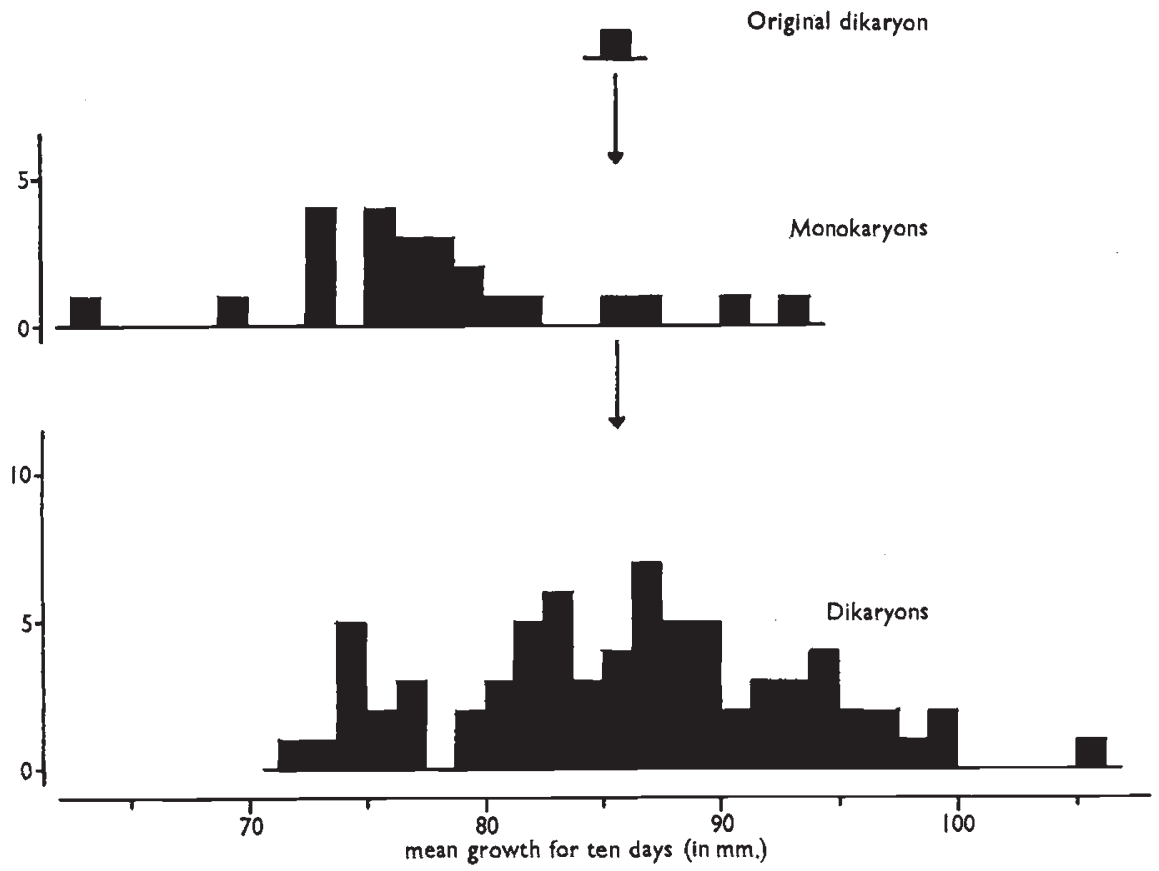

FIG. 3.-A frequency diagram showing mean growth rates for ten days, of dikaryon No. 2 and its descendants.

TABLE 5

Analysis of variance

\begin{tabular}{|c|c|c|c|c|c|c|}
\hline \multirow{2}{*}{ Item } & \multicolumn{3}{|c|}{$\begin{array}{l}\text { Dikaryon No. I } \\
\text { (data from tables I, 2) }\end{array}$} & \multicolumn{3}{|c|}{$\begin{array}{l}\text { Dikaryon No. } 2 \\
\text { (data from tables } 3,4 \text { ) }\end{array}$} \\
\hline & d.f. & M.S. & V.R. & d.f. & M.S. & V.R. \\
\hline $\begin{aligned} \text { Dikaryons: } & \text { common parents }(a-f) \\
& \text { common parents }(g-l) \\
& \text { parents interaction }\end{aligned}$ & $\begin{array}{r}5 \\
5 \\
25\end{array}$ & $\begin{array}{l}\text { I } 73 \cdot 92 \dagger \\
\text { I } 31 \cdot 35 \dagger \\
\text { I } 6 \cdot 14\end{array}$ & $\begin{array}{l}21 \cdot 60^{*} \\
16 \cdot 3^{*} \\
2 \cdot 01^{*}\end{array}$ & $\begin{array}{r}5 \\
5 \\
25\end{array}$ & $\begin{array}{l}512 \cdot 12 \dagger \\
118 \cdot 82 \\
63 \cdot 86\end{array}$ & $\begin{array}{l}100 \cdot 22^{*} \\
23^{*} \cdot 1^{*} \\
12 \cdot 47^{*}\end{array}$ \\
\hline $\begin{array}{l}\text { Blocks } \\
\text { Blocks } \times \text { dikaryons (error) }\end{array}$ & $\begin{aligned} 3 \\
103\end{aligned}$ & $\begin{array}{r}70 \cdot 19 \\
8 \cdot 05\end{array}$ & $8 \cdot 72^{*}$ & $\begin{array}{r}3 \\
104\end{array}$ & $\begin{array}{r}41 \cdot 45 \\
5 \cdot 12\end{array}$ & $8 \cdot 10^{*}$ \\
\hline $\begin{aligned} \text { Dikaryons: } & \text { common parents }(m-r) \\
& \text { common parents }(s-z) \\
& \text { parents interaction }\end{aligned}$ & $\begin{array}{r}5 \\
5 \\
25\end{array}$ & $\begin{array}{l}94 \cdot 72 \dagger \\
97 \cdot 43^{\dagger} \\
16 \cdot 23\end{array}$ & $\begin{array}{r}13 \cdot 14^{*} \\
13 \cdot 1^{*} \\
2 \cdot 25^{*}\end{array}$ & $\begin{array}{r}5 \\
5 \\
25\end{array}$ & $\begin{array}{c}1051 \cdot 88 \dagger \\
279 \cdot 45 \dagger \\
27 \cdot 27\end{array}$ & $\begin{array}{r}57 \cdot 23^{*} \\
4^{1} \cdot 77^{*} \\
4 \cdot 08^{*}\end{array}$ \\
\hline $\begin{array}{l}\text { Blocks } \\
\text { Blocks } \times \text { dikaryons (error) }\end{array}$ & $\begin{array}{r}3 \\
102\end{array}$ & $\begin{array}{r}121 \cdot 21 \\
7 \cdot 21\end{array}$ & $16.81 *$ & $\begin{array}{r}3 \\
104\end{array}$ & $\begin{aligned} 71 \cdot 15 \\
6 \cdot 69\end{aligned}$ & $10 \cdot 64^{*}$ \\
\hline
\end{tabular}

* Significant V.R. ( $\mathrm{P} \leqq 0 \cdot 0 \mathrm{I})$, tested against the error item.

$\dagger$ Significant V.R. ( $\left.\mathrm{P} \leqq 0^{\circ} \cdot 01\right)$, when tested against the parents' interaction.

Suppose we have a design in which $f$ "fathers" (or monokaryons of one mating type) cross in all possible combinations with $m$ "mothers" (monokaryons of the compatible mating type). We grow $n$ replicates 
from each of the $f . m$ progeny obtained, in $n$ blocks. From the analysis of variance the following mean squares will be expected:-

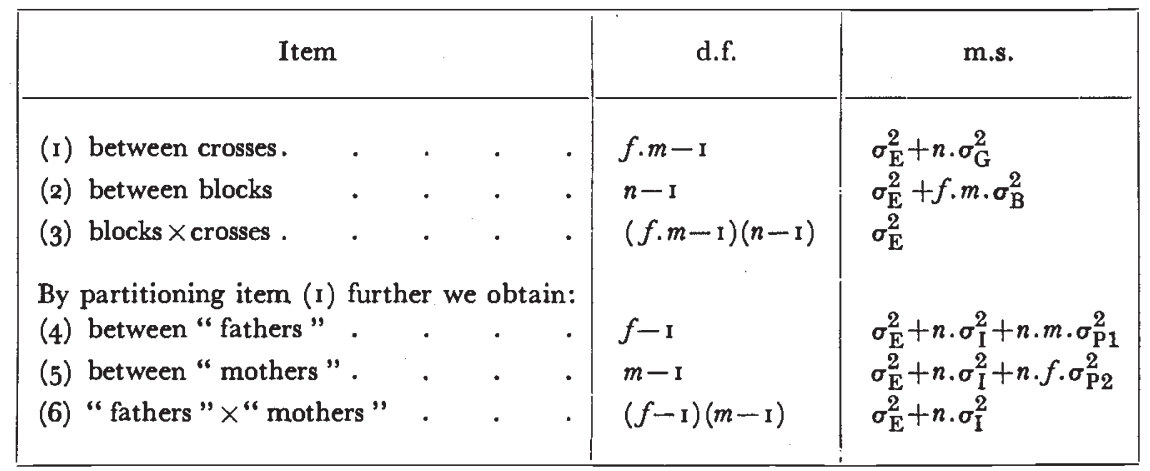

And the estimates of the components will be:-

$$
\begin{array}{lll}
\text { estimate of } \sigma_{\mathrm{E}}^{2}: & (3) \\
\text { estimate of } \sigma_{\mathrm{I}}^{2}: & ((6)-(3)) / n \\
\text { estimate of } \sigma_{\mathrm{P} 1}^{2}: & ((4)-(6)) /(n . m) \\
\text { estimate of } \sigma_{\mathrm{P} 2}^{2}: & ((5)-(6)) /(n . f) .
\end{array}
$$

Where $\sigma_{\mathrm{E}}^{2}$ is the environmental component of variation, $\sigma_{\mathrm{I}}^{2}$ is the non-additive genetical component and appears with a coefficient $n$ because it was obtained from sums, each of which is based on $n$ observations, $\sigma_{\mathrm{P} 1}^{2}$ and $\sigma_{\mathrm{P} 2}^{2}$ are additive genetical components, and have coefficients of $n . m$ and $n . f$ which are the total number of observations relating to each "father" or " mother" respectively. ( $\sigma_{\mathrm{G}}^{2}$ will be the total genetical component of variation and $\sigma_{\mathrm{B}}^{2}$-the blocks' component.)

It is possible to divide the total observed variance, $V_{\mathrm{T}}$, into genetical and environmental components, $V_{\mathrm{G}}$ and $V_{\mathrm{E}}$, such that $V_{\mathrm{T}}=V_{\mathrm{G}}+V_{\mathrm{E}}$. We can further subdivide $V_{\mathrm{G}}$ as $V_{\mathrm{T}}=V_{\mathrm{P}}+V_{\mathrm{I}}+V_{\mathrm{E}}$ where $V_{\mathrm{P}}$, the additive component comes from the "fathers" and "mothers" items in the above analysis of variance, that is $V_{\mathrm{P}}$ is an estimate of $\sigma_{\mathrm{P} 1}^{2}+\sigma_{\mathrm{P} 2}^{2}$, and $V_{\mathrm{I}}$ is an estimate of $\sigma_{I}^{2}$.

The expected mean squares in the analysis of variance of the growth rates of dikaryons are as follows.

\begin{tabular}{|lr|r|l|}
\hline \multicolumn{1}{|c|}{ Item } & d.f. & \multicolumn{1}{|c|}{ m.s. } \\
\cline { 1 - 1 } Common parents $(a-f)$ &. & 5 & \\
\cline { 1 - 2 } Common parents $(g-l)$ &. & 5 & $\sigma_{\mathrm{E}}^{2}+4 \sigma_{\mathrm{I}}^{2}+24 \sigma_{\mathrm{P} 1}^{2}$ \\
Parents interaction &. & 25 & $\sigma_{\mathrm{E}}^{2}+4 \sigma_{\mathrm{I}}^{2}+24 \sigma_{\mathrm{P} 2}^{2}$ \\
Blocks $\times$ dikaryons &. & 105 & $\sigma_{\mathrm{E}}^{2}$ \\
\hline
\end{tabular}

The estimates $V_{\mathrm{E}}, V_{\mathrm{I}}$ and $V_{\mathrm{P}}$ derived from the analysis of variance are given in table 6 , and are also expressed as percentages of $V_{\mathrm{T}}$. 
TABLE 6

Estimates of the components of variation obtained from the mean squares in table 5

\begin{tabular}{|c|c|c|c|c|}
\hline $\begin{array}{l}\text { Component } \\
\text { Source }\end{array}$ & $V_{\mathbb{E}}$ & $V_{I}$ & $V_{\mathrm{P}}$ & $V_{T}$ \\
\hline $\begin{array}{c}\text { Dikaryon No. I: } \\
\underset{(a-f) \times(g-l)}{(m-r) \times(s-z)} .\end{array}$ & $\begin{array}{c}8 \cdot 05 \\
(37 \cdot 5 \text { per cent. }) \\
7 \cdot 21 \\
(44.7 \text { per cent. })\end{array}$ & $\begin{array}{c}2 \cdot 02 \\
(9.4 \text { per cent.) } \\
2 \cdot 25 \\
\text { (14.0 per cent.) }\end{array}$ & $\begin{array}{c}\text { I } \cdot 37 \\
(53 \cdot 1 \text { per cent. }) \\
6 \cdot 65 \\
(41 \cdot 3 \text { per cent. })\end{array}$ & $\begin{array}{l}21 \cdot 44 \\
16 \cdot 11\end{array}$ \\
\hline $\begin{array}{c}\text { Dikaryon No. 2: } \\
(a-f) \times(g-l) \\
(m-r) \times(s-z)\end{array}$. & $\begin{array}{c}5.12 \\
\text { (12.6 per cent.) } \\
6.69 \\
\text { (10.3 per cent.) }\end{array}$ & $\begin{array}{c}14.68 \\
(36 \cdot 0 \text { per cent. }) \\
5 \cdot 14 \\
(7 \cdot 9 \text { per cent. })\end{array}$ & $\begin{array}{c}20 \cdot 97 \\
(5 \mathrm{I} \cdot 4 \text { per cent. }) \\
(8 \mathrm{r} \cdot 8 \text { per cent. })\end{array}$ & $\begin{array}{l}40 \cdot 77 \\
65 \cdot 03\end{array}$ \\
\hline
\end{tabular}

\section{THE NATURE OF THE PARENTS' INTERACTION}

In the foregoing section, the genetic variance $V_{\mathrm{G}}$ has been divided into an additive component, $V_{\mathrm{P}}$, and a non-additive component, $V_{\mathrm{I}}$, which results from interaction between the two parental genotypes which contribute to the dikaryon. The nature of this interaction still needs clarification; its source can be non-allelic interaction or allelic interaction, i.e. dominance, or both. By carrying the analysis further, it can be shown that dominance by itself is sufficient to explain all the variation due to interaction between parental genotypes. We shall, therefore, ignore non-allelic interactions in the following model.

$\sigma_{\mathrm{G}}^{2}, \sigma_{\mathrm{I}}^{2}$ and $\sigma_{\mathrm{P} 1}^{2}+\sigma_{\mathrm{P} 2}^{2}$ can be defined by using Mather's (1949) notation. In a simple model of one gene with two alleles $\mathrm{A}-\mathrm{a}$, the values of genotypes and means of arrays will be:

Monokaryotic " mothers"

Monokaryotic

\begin{tabular}{|c|c|c|c|}
\hline \multicolumn{4}{|c|}{ Monokaryotic " mothers" } \\
\hline & $\begin{array}{l}\mathrm{A} \\
u\end{array}$ & $\begin{array}{l}a \\
v\end{array}$ & $\begin{array}{l}\text { array } \\
\text { means }\end{array}$ \\
\hline $\begin{array}{l}\mathrm{A} \\
u\end{array}$ & $\begin{array}{l}d \\
u^{2}\end{array}$ & $\begin{array}{l}h \\
u v\end{array}$ & $u d+v h$ \\
\hline $\begin{array}{l}a \\
v\end{array}$ & $\begin{array}{l}h \\
u v\end{array}$ & $\frac{-d}{v^{2}}$ & $-v d+u h$ \\
\hline $\begin{array}{l}\text { array } \\
\text { means }\end{array}$ & $u d+v h$ & $-v d+u h$ & $(u-v) d+2 u v h$ \\
\hline
\end{tabular}

Where $d$ is half the difference between the values of the two homozygotes AA and aa, $h$ is the deviation of the heterozygote Aa from the 
mid-value of the two homozygotes, and $u$ and $v$ are the frequencies of the parents containing $\mathrm{A}$ and a alleles, respectively $(u+v=\mathrm{I})$.

The expected variances will be:-

$$
\begin{aligned}
& \sigma_{\mathrm{G}}^{2}=u^{2} d^{2}+2 u v h^{2}+v^{2} d^{2}-((u-v) d+2 u v h)^{2} \\
& =2 u v\left(d^{2}-2(u-v) d h+\left(u^{2}+v^{2}\right) h^{2}\right) \\
& \sigma_{\mathrm{P} 1}^{2}+\sigma_{\mathrm{P} 2}^{2}=2\left(u(u d+v h)^{2}+v(-v d+u h)^{2}-((u-v) d+2 u v h)^{2}\right) \\
& \sigma_{\mathrm{I}}^{2}=\sigma_{\mathrm{G}}^{2}-\left(\sigma_{\mathrm{P} 1}^{2}+\sigma_{\mathrm{P} 2}^{2}\right)=4 u^{2} v^{2} h^{2} \\
& =2 u v(d-(u-v) h)^{2}
\end{aligned}
$$

and over several independent genes,

$$
\begin{aligned}
\sigma_{\mathrm{P} 1}^{2}+\sigma_{\mathrm{P} 2}^{2} & =\Sigma_{2} u v(d-(u-v) h)^{2} & & =\frac{1}{2} D_{\mathrm{R}} \\
\sigma_{\mathrm{I}}^{2} & =\Sigma_{4} u^{2} v^{2} h^{2} & & =\frac{1}{4} H_{\mathrm{R}} \\
\sigma_{\mathrm{G}}^{2} & =\Sigma_{2 u v}(d-(u-v) h)^{2}+\Sigma_{4} u^{2} v^{2} h^{2} & & =\frac{1}{2} D_{\mathrm{R}}+\frac{1}{4} H_{\mathrm{R}} .
\end{aligned}
$$

Where $D_{\mathrm{R}}$ and $H_{\mathrm{R}}$ correspond to Mather's $D$ and $H$ for random mating. These expectations are in fact identical with those obtained by Comstock and Robinson (1948) and by Jinks (1954). In addition to the statistics which can be obtained from the analysis of variance, by following the approach of Jinks to the analysis of diallel crosses, one can recognise two further statistics, namely the variances and covariances of members of arrays; an array being defined as all the crosses involving any one parental line (any one monokaryotic strain). The expectations for variances within arrays, $V_{r}$, and for covariances between crosses within each array and the array means of non-common parents, $W_{y}^{\prime}$, can be derived as follows. Note, the $W_{r}^{\prime}$ statistic is used here instead of the usual $W_{r}$ because parental dikaryotic measurements and hence real $W_{r}$ values are not available.

$V_{r}$ for array $\mathrm{A}: u d^{2}+v h^{2}-(u d+v h)^{2}=u v(d-h)^{2}$

$V_{r}$ for array a: $u h^{2}+v(-d)^{2}-(u h-v d)^{2}=u v(d+h)^{2}$

$W_{r}^{\prime}$ for array $\mathrm{A}: u d(u d+v h)+v h(u h-v d)-(u d+v h)((u-v) d+2 u v h)$

$$
=u v d^{2}-2 u^{2} v d h+u v(u-v) h^{2}
$$

$W_{r}^{\prime}$ for array a: $u h(u d+v h)-v d(u h-v d)-(u h-v d)((u-v)+2 u v h)$

$$
=u v d^{2}+2 u v^{2} d h-u v(u-v) h^{2} .
$$

It is possible to predict the slope of array values plotted on a $W_{r}^{\prime}$ versus $V$, graph:-

The expectation of $\frac{W_{r}^{\prime}(\mathrm{a})-W_{r}^{\prime}(\mathrm{A})}{V_{r}(\mathrm{a})-V_{r}(\mathrm{~A})}$ is $\frac{2 u v h(d-(u-v) h)}{4 u v d h}=\frac{\mathrm{I}}{2}-\frac{(u-v) h}{2 d}$.

This expectation shows that the $W_{r}^{\prime} / V_{r}$ graph will have a slope of $\frac{1}{2}$ when the frequencies of both alleles are equal. In crosses, however, when $u \neq v$, the sign of $(u-v)$ and of $h$ will determine whether the slope will be greater or smaller than $\frac{1}{2}$. It is also clear that arrays of parents containing dominant alleles will determine points nearer to the origin of axes on the graph, than arrays containing recessive alleles. 

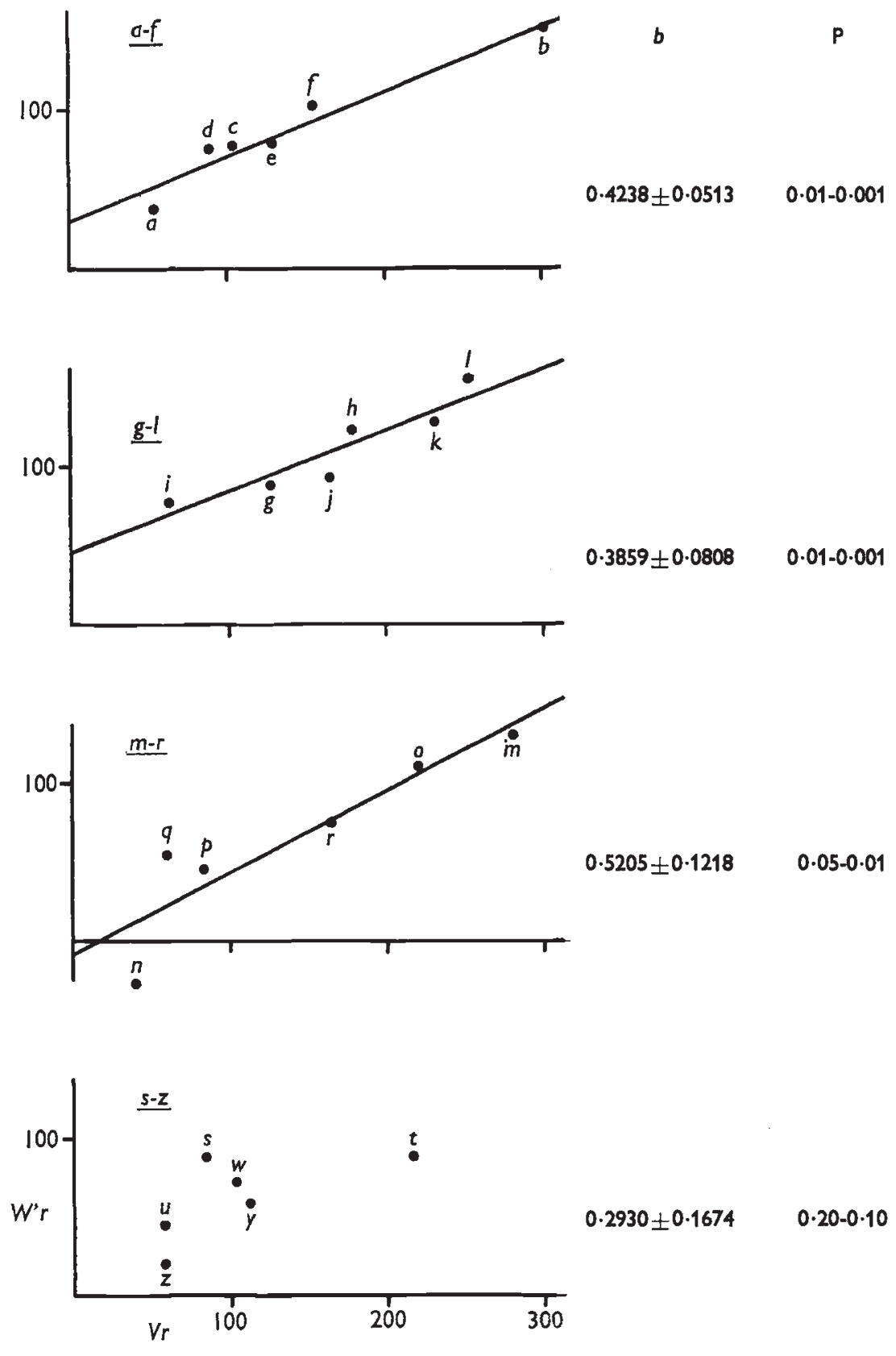

FIG. 4.- $W_{r}^{\prime} / V_{r}$ graphs obtained from dikaryotic progeny of dikaryon No. I (data given in tables I and 2). $b$ is the slope of the regression line, $\mathrm{P}$ is the significance level for the deviation from a slope of zero.

The same expectations will hold also for several independent genes which effect the same character, provided the values of $u$ are equal for all the genes. 

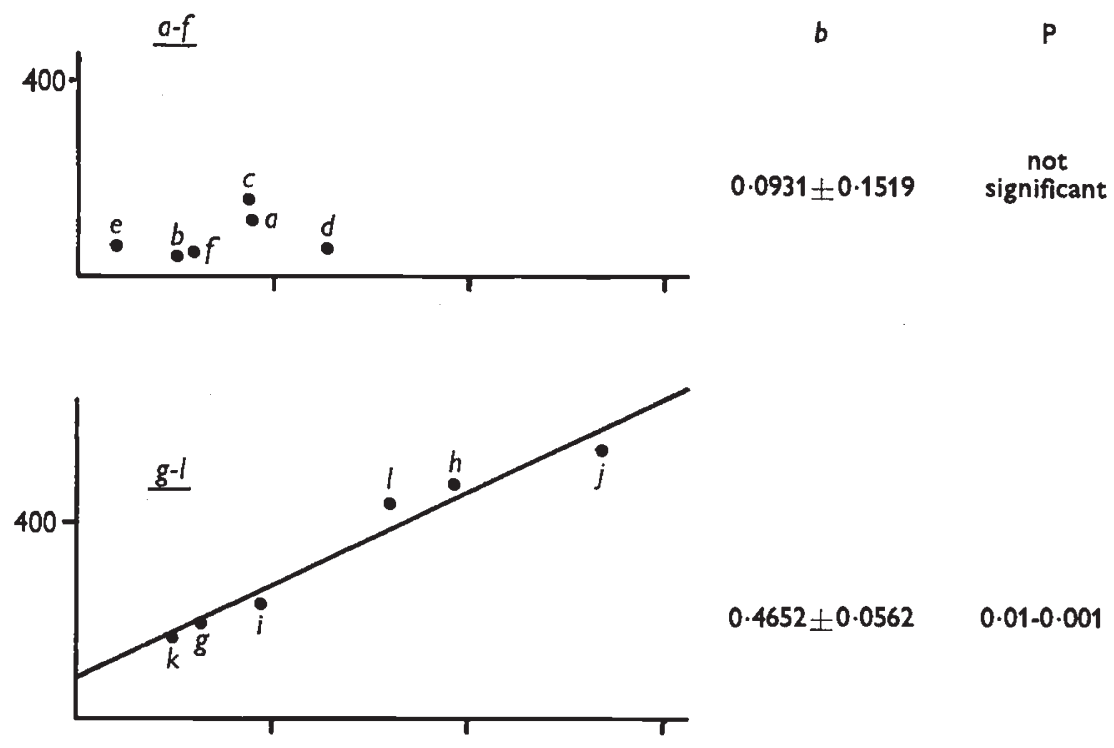

$0.4652 \pm 0.0562 \quad 0.01-0.001$

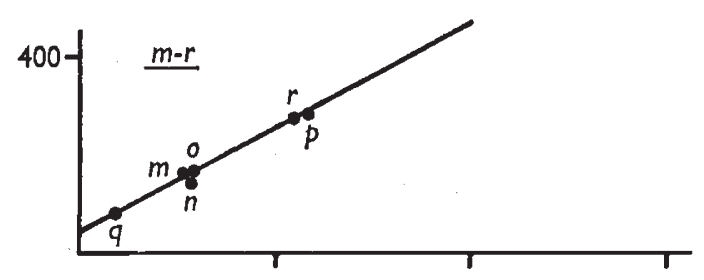

$0.5334 \pm 0.0282 \quad<0.001$

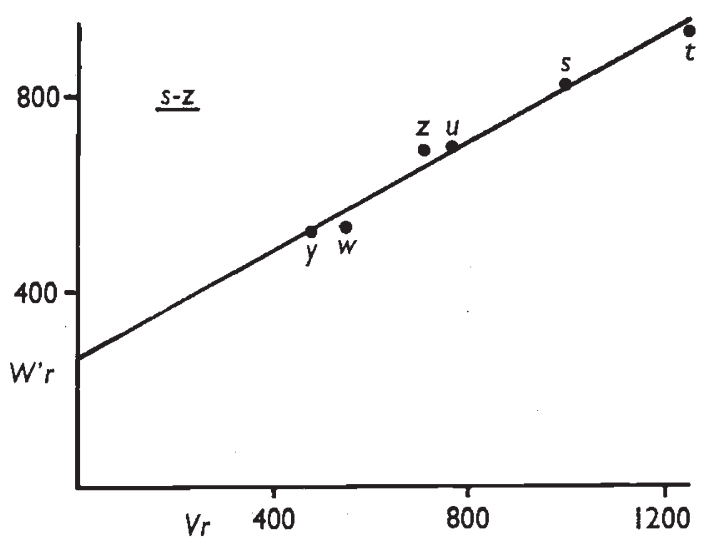

$0.5472 \pm 0.0438 \quad<0.001$

Frg. 5. - $W_{r}^{\prime} / V_{r}$ graphs obtained from dikaryotic progeny of dikaryon No, 2 (data given in tables 3 and 4). For explanation see fig. 4 .

The arrays variances and covariances obtained from the data summarised in tables $1,2,3$ and 4 were calculated and plotted in figs. 4 and 5. The slopes of the regression lines and the levels of significance for their differences from $o$ are also given. 

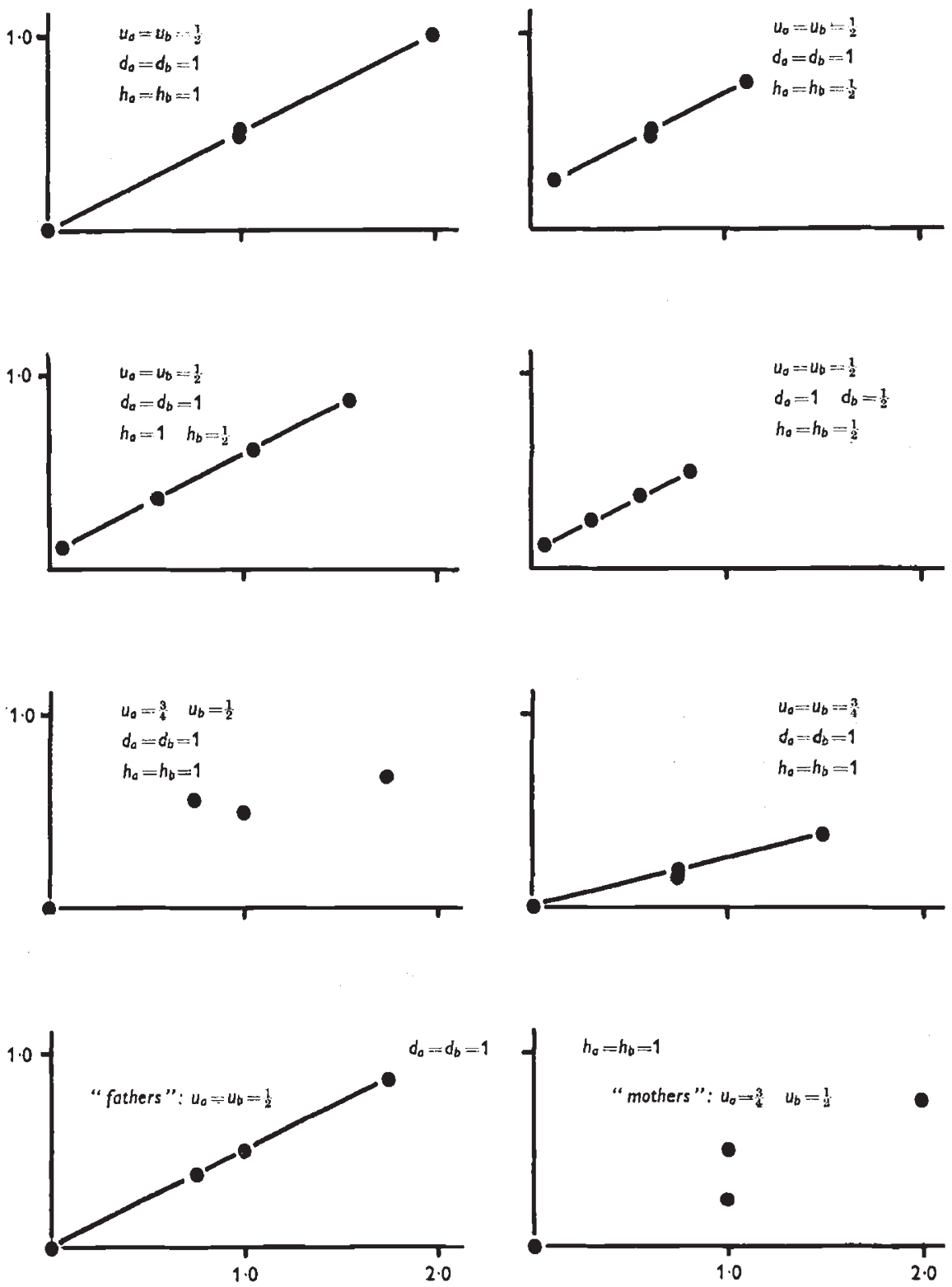

FIG. 6.-Theoretical $W_{r}^{\prime} / V_{r}$ graphs based on a model containing two independent loci, $\mathrm{A}-\mathrm{a}$ and B-b, additivity, and dominance.

In each dikaryon, three out of the four sets of parents clearly agree with the expectation (i.e. a significant regression of $W_{r}^{\prime} / V_{r}$ graphs), based on the model which assumes additivity and dominance only. The disagreement with the model shown by parents $(s-z)$ of dikaryon No. $I$ and parents $(a-f)$ of dikaryon No. 2 is not real, and can be accounted for by sampling errors. As shown in fig. 6, discrepancies 
from an expected regression line and the scatter of the $W_{r}^{\prime} / V_{r}$ points on the graph can be caused by different $u$ values for different genes. Since in each experiment random samples of monokaryons originating from one dikaryon were used one can assume that $u=v=\frac{1}{2}$ for all genes within the sampling error, providing of course that there is no differential viability. The validity of the assumption is confirmed by the fact that none of the eight $W_{r}^{\prime} / V_{r}$ regression coefficients differ significantly from $\frac{1}{2}$. In these circumstances we can simplify the expected values of $D_{\mathrm{R}}$ and $H_{\mathrm{R}}$ by putting $u=v=\frac{1}{2}$ so that $D_{\mathrm{R}}=\Sigma d^{2}$ and $H_{\mathrm{R}}=\Sigma h^{2}$ (see Mather, 1949).

Another conclusion which can be drawn from figs. 4 and 5 is that dominance in the different loci controlling dikaryotic growth is ambidirectional. Thus some of the dominant arrays, which determine points near the origin of the axes on the $W_{r}^{\prime} / V_{r}$ graphs, have high mean values, and others have low mean values, and similarly for the recessive arrays.

Before leaving the problem of the $W_{r}^{\prime} / V_{r}$ graphs, it should be noted that in two cases (in $(m-r) \times(s-z)$ of dikaryon No. I, and in $(a-f) \times$ $(g-l)$ of dikaryon No. 2) the points based on one set of common parents give highly significant regressions, while those based on the other set of common parents give non-significant regressions. This appears to be a contradiction since the same data are used for both graphs. The model situation graphed in fig. 6 (the last two graphs), however, shows how this can come about. Thus if one set of parents has $u_{a}=u_{b}$ and the other deviates from this, then the former will give a good linear regression and the latter will not.

\section{THE CORRELATION BETWEEN DIKARYONS AND PARENTAL MONOKARYONS IN RESPECT TO GROWTH RATE}

In this section we shall estimate how much of the variation among dikaryons can be related to variation in the parental monokaryons.

The growth rates of the monokaryons, given in italics in the margins of tables I, 2, 3 and 4, have not so far been used in the analysis. The experiments, however, were designed to provide estimates of the correlation between the growth rates of monokaryons and dikaryons, each dikaryon having been grown in the same experiment with its monokaryotic parents. For each dikaryon, the value of dikaryotic growth rate and the mean value of the parental monokaryotic growth rates determine a point in the graphs shown in fig. 7 or fig. 8 (values from tables 1,2 , or 3,4 respectively).

These graphs show a correlation between the growth rates of the dikaryons and their parental monokaryons. Regression analyses of dikaryotic values on their mid-monokaryotic parental values are as shown in table 7 on p. 644 .

In three of the four analyses, the linear regression mean squares are significant when tested against the remainder, and in all four 
analyses the remainder mean squares are significant when tested against the error. It seems, therefore that while a significant part of the variation in the growth rates of dikaryons can be related to variation in the monokaryotic parents, there is a significant remainder which

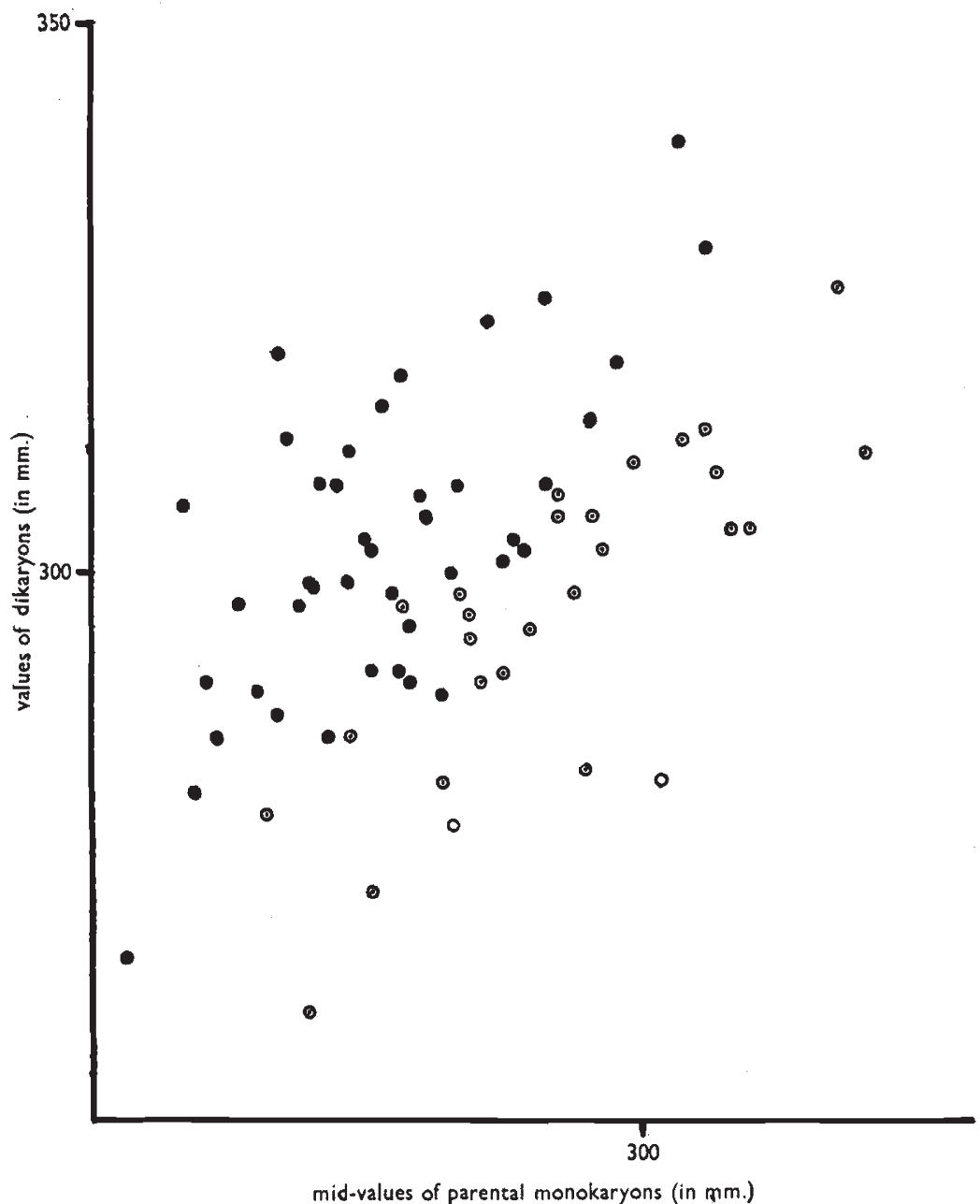

FiG. 7.-The relationships between values of dikaryotic growth rates and mid-values of parental monokaryons, for 72 dikaryons originated from dikaryon No. I. Dikaryons which grow faster than both parental monokaryons are shown as $\mathbf{0}$, dikaryons which grow at a rate intermediate between the two parental monokaryotic growth rates are shown as $\odot$ and the dikaryons which grow slower than both parental monokaryons are represented by $O$.

cannot be accounted for in this way. These analyses provide us with an alternative method of partitioning the variation among dikaryons into components, to the one summarised in table 6 . In the present analysis $V_{\mathrm{G}}=V_{\mathrm{M}}+V_{\mathrm{NM}}$ where $V_{\mathrm{G}}$ is again the total genetical variation of diakryotic growth rates, $V_{M}$ is that part of the variation which is correlated with the mean growth rate of parental monokaryons, and 


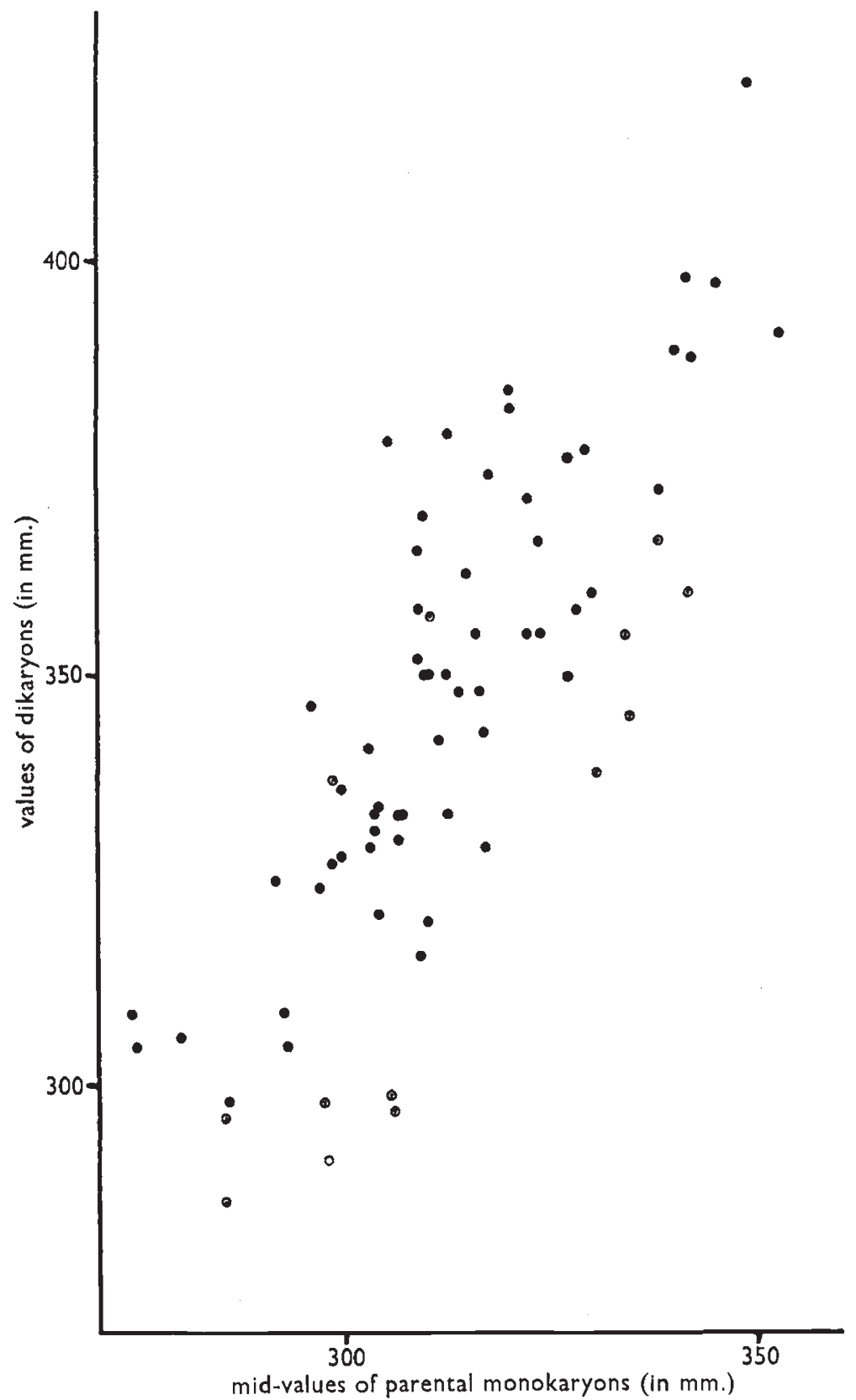

FIG. 8.-The relationship between values of dikaryotic growth rates and mid-values of parental monokaryons, for 72 dikaryons originated from dikaryon No. 2. For explanation see fig. 7 .

$V_{\mathrm{NM}}$ represent the fraction of the genetical variation which cannot be predicted from variation among parental monokaryons. From these definitions $V_{\mathrm{M}}=r^{2} V_{\mathrm{G}}$ where $r$ is the correlation between the growth 
TABLE 7

Regression analyses

\begin{tabular}{|c|c|c|c|c|c|c|c|c|}
\hline \multirow{2}{*}{ Item } & \multicolumn{4}{|c|}{$\begin{array}{c}\text { Dikaryon No. I } \\
\text { (data from tables I and 2) }\end{array}$} & \multicolumn{4}{|c|}{$\begin{array}{c}\text { Dikaryon No. } 2 \\
\text { (data from tables } 3 \text { and } 4 \text { ) }\end{array}$} \\
\hline & d.f. & M.S. & V.R.† & $\mathbf{P}$ & d.f. & M.S. & V.R.† & $\mathbf{P}$ \\
\hline $\begin{array}{l}\quad(a-f) \times(g-l) \\
\text { Regression dikaryons on mid- } \\
\text { monokaryons : } \\
\text { Remainder } \\
\text { Error (blocks } \times \text { dikaryons) }\end{array}$ & $\begin{array}{r}\mathrm{I} \\
34 \\
103\end{array}$ & $\begin{array}{r}327.62 \\
47.12 \\
8.05\end{array}$ & $\begin{array}{l}6 \cdot 95 \\
5 \cdot 85\end{array}$ & $\begin{array}{c}0.01-0.05 \\
<0.001\end{array}$ & $\begin{array}{r}I \\
34 \\
104\end{array}$ & $\begin{array}{r}2168.33 \\
75 \cdot 97 \\
5 \cdot 12\end{array}$ & $\begin{array}{l}28 \cdot 54 \\
14 \cdot 84\end{array}$ & $\begin{array}{l}<0.001 \\
<0.001\end{array}$ \\
\hline $\begin{array}{l}\quad(m-r) \times(s-z) \\
\text { Regression dikaryons on mid- } \\
\text { monokaryons }: \\
\text { Remainder } \cdot \\
\text { Error (blocks } \times \text { dikaryons) }\end{array}$ & $\begin{array}{r}\mathrm{I} \\
34 \\
102\end{array}$ & $\begin{array}{r}102 \cdot 44 \\
41 \cdot 95 \\
7.21\end{array}$ & $\begin{array}{l}2.44 \\
5.82\end{array}$ & $\begin{array}{c}0.10-0.20 \\
<0.001\end{array}$ & $\begin{array}{r}I \\
34 \\
104\end{array}$ & $\begin{array}{r}2210.74 \\
150.82 \\
6.69\end{array}$ & $\begin{array}{l}14 \cdot 16 \\
22 \cdot 54\end{array}$ & $\begin{array}{l}<0.001 \\
<0.001\end{array}$ \\
\hline
\end{tabular}

* This error is the same as in the analysis of variance (p. 634).

$\dagger$ The regression mean squares have been tested against the remainder mean squares because the latter are always significant when tested against the error mean squares.

rates of the dikaryons and the means of the growth rates of the monokaryotic parents. $r^{2}$ can be derived from the regression analyses as follows.

$$
\text { Regression } \mathrm{SS}=\frac{\left(\mathrm{SCP}\left(\mathrm{dik}_{\mathrm{k}} \times \text { monok. }\right)\right)^{2}}{\mathrm{SS} \text { monok. }}
$$

Total dikaryons SS = SS dik.

$$
\frac{\text { Regression SS }}{\text { Total dikaryons SS }}=\frac{(\mathrm{SCP}(\text { dik. } \times \text { monok. }))^{2}}{\mathrm{SS} \mathrm{dik.} \times \mathrm{SS} \text { monok. }}=r^{2} \text {. }
$$

Values of $r^{2}$ and the partition of the total variance of dikaryons based on these values are presented in table 8 . It can be seen from this table that the amount of variation which can be related to differences among monokaryotic parents, $V_{\mathrm{M}}$, is small in comparison with the additive variation (table 6), $V_{\mathrm{P}}$, among the dikaryons. An interpretation of this will be given in the discussion.

In general, dikaryons grow faster than monokaryons (figs. 2 and 3 ). By comparing each dikaryotic growth rate with that of its two parental monokaryons, one finds three categories of relationships between dikaryon and monokaryons: (i) Most dikaryons grow faster than both parental monokaryons, (ii) others have a growth rate intermediate between the parental monokaryotic values and (iii) a few grow slower than either parental monokaryon. Table 9 summarises these relationships which are shown in figs. 7 and 8. 
TABLE 8

Estimates of the components of variation obtained from the regression analyses reported in table 7

\begin{tabular}{|c|c|c|c|c|c|}
\hline Component & $r^{2}$ & $V_{M}=r^{2} V_{G}$ & $V_{\mathrm{NM}}=\left(1-r^{2}\right) V_{\mathrm{G}}$ & $V_{\mathbf{E}}$ & $V_{\mathbf{T}}$ \\
\hline $\begin{array}{l}\text { Dikaryon No. 1: } \\
(a-f) \times(g-l) \\
(m-r) \times(s-z)\end{array}$ & $\begin{array}{l}0.1698 \\
0.0670\end{array}$ & $\begin{array}{c}2.27 \\
\text { (10.6 per cent.) } \\
0.60 \\
(3.7 \text { per cent.) }\end{array}$ & $\begin{array}{c}11 \cdot 12 \\
\left(5^{1} \cdot 9 \text { per cent. }\right) \\
8 \cdot 3^{1} \\
\left(5^{1} \cdot 6 \text { per cent. }\right)\end{array}$ & $\begin{array}{c}8.05 \\
(37.5 \text { per cent.) } \\
7 \cdot 21 \\
\text { ( } 44.7 \text { per cent.) }\end{array}$ & $\begin{array}{l}21 \cdot 44 \\
16 \cdot 12\end{array}$ \\
\hline $\begin{array}{l}\text { Dikaryon No. 2: } \\
(a-f) \times(g-l) \\
(m-r) \times(s-z)\end{array}$ & $\begin{array}{l}0.45^{64} \\
0.3019\end{array}$ & $\begin{array}{c}16 \cdot 27 \\
(39 \cdot 9 \text { per cent.) } \\
17 \cdot 61 \\
(27 \cdot 1 \text { per cent.) }\end{array}$ & $\begin{array}{c}19 \cdot 3^{8} \\
(47 \cdot 5 \text { per cent. }) \\
40^{\circ} 73 \\
(62.6 \text { per cent. })\end{array}$ & $\begin{array}{c}5.12 \\
\text { (12.6 per cent.) } \\
6.69 \\
\text { (10.3 per cent.) }\end{array}$ & $\begin{array}{l}40 \cdot 77 \\
65 \cdot 03\end{array}$ \\
\hline
\end{tabular}

TABLE 9

The three relationships between the growth rates of dikaryons and parental monokaryons

\begin{tabular}{|c|c|c|c|}
\hline & $\begin{array}{l}\text { (i) Dikaryon faster } \\
\text { than monokaryons }\end{array}$ & $\begin{array}{l}\text { (ii) Dikaryon } \\
\text { intermediate }\end{array}$ & $\begin{array}{l}\text { (iii) Dikaryon slower } \\
\text { than monokaryons }\end{array}$ \\
\hline Dikaryon No. I . & 43 & 27 & 2 \\
\hline Dikaryon No. 2 . & 59 & 12 & 1 \\
\hline
\end{tabular}

\section{DISCUSSION}

The biometrical analysis of the growth rates of dikaryons has clarified the nature of the genetic control of its variation. The outcome of the analysis shows that quantitative characters in fungi are not less suitable for biometrical analysis than comparable characters in higher plants or animals. On the contrary, the estimates of the various genetical and environmental components of variation obtained appear to agree with one another even better than in most biometrical analyses. In addition to these estimates, the $W_{r}^{\prime} \mid V_{r}$ graphs show a very good agreement with a model which assumes additivity and dominance as the only genetical sources of variation.

Two main factors have helped us to obtain these satisfying results: first, the simple genetic situation with the absence of non-allelis interaction, and second, the stability of the controlled environment, which resulted in only a relatively small, and constant, environmental component of variation (see the $V_{\mathrm{E}}$ column in tables 6 and 8 ).

On the other hand, there are two significant differences between 
the estimates obtained from dikaryon No. I and those obtained from No. 2. Firstly, the total amount of variation, $V_{\mathrm{T}}$, is much higher in No. 2 than in No. I although the estimates of the environmental component of variation, $V_{\mathrm{E}}$, are surprisingly similar. The simplest explanation is that the difference in $V_{\mathrm{T}} \mathrm{s}$ lies in a greater segregation of genetic factors determining growth rate in the fruiting bodies of dikaryon No. 2 compared with No. I. This in turn would indicate a higher degree of heterozygosity at loci controlling rate of growth in the original dikaryon No. 2. Secondly, the estimates of the proportion of variation which is correlated with the growth rates of parental monokaryons, $V_{\mathrm{M}}$ and $r^{2}$, also differ between the original monokaryons. This difference seems to be more fundamental, but it could be explained on a similar basis to the one which has been discussed already, namely that in comparison with dikaryon No. I dikaryon No. 2 is heterozygous for more loci which determine the growth rates of monokaryons as well as the growth rates of dikaryons.

The biometrical analysis shows that additivity and dominance exist in dikaryons, and behave in a manner similar to that found in diploids. Allelic interaction, i.e. dominance, seems to operate between nuclei (in dikaryons) separated by two nuclear membranes as well as within a nucleus (in diploids). Raper and Krongelb (1958) support the similarity between diploids and dikaryons: they have shown that Bug's ear and Corraloid, which are two abnormal characters of the fruiting bodies in Schizophyllum commune, are in fact determined by major genes which show dominance in the dikaryotic state.

The analysis of array variances and covariances shows that dominance in loci effecting growth of dikaryons is ambi-directional, that is at some loci the increasing alleles are dominant while at other loci it is the decreasing alleles that are dominant. Such a situation suggests that the character has been subjected to stabilising selection as the main force of natural selection. Thus growth rate in Schizophyllum is comparable with chaetæ number in Drosophila (Breese and Mather, 196o; Mather, 196o), that is we have a central optimum for these characters with both extremes at a disadvantage relative to the more central values.

An incidental result of adopting the biometrical approach is that it has solved a long-standing controversy, namely the relation between the growth rates of monokaryons and dikaryons in the Hymenomycetes. Buller (193I, p. 199) writes:-

"If exact comparative measurements of the rate of growth of a diploid mycelium of $C$. lagopus and of the two haploids from which it has been derived were to be made, it would probably be found that the diploid always grows slightly more rapidly than either of the haploids. Possibly it is a general rule in the Hymenomycetes that diploid mycelia grow faster than their component haploids; but whether this is so or not needs to be decided by exact investigation."

Several such investigations have been reported in the literature, but the different generalisations and statements based on them are 
conflicting. We ourselves (Groft and Simchen, in preparation) have found that six dikaryons of Collybia velutipes collected in the Midlands, England, grow faster than both component monokaryons. The conclusions derived from these earlier comparisons are summarised in table ı.

The results of the experiments reported in the present paper give an answer to the contradictory statements found in the literature. One can see in table 9 that in most combinations dikaryons grow faster than both parental monokaryons, but in several cases the dikaryotic growth rate is intermediate. There are even rare combinations in

TABLE Io

Relations between growth-rates of dikaryons and parental monokaryons in the Hymenomycetes, reported in the literature

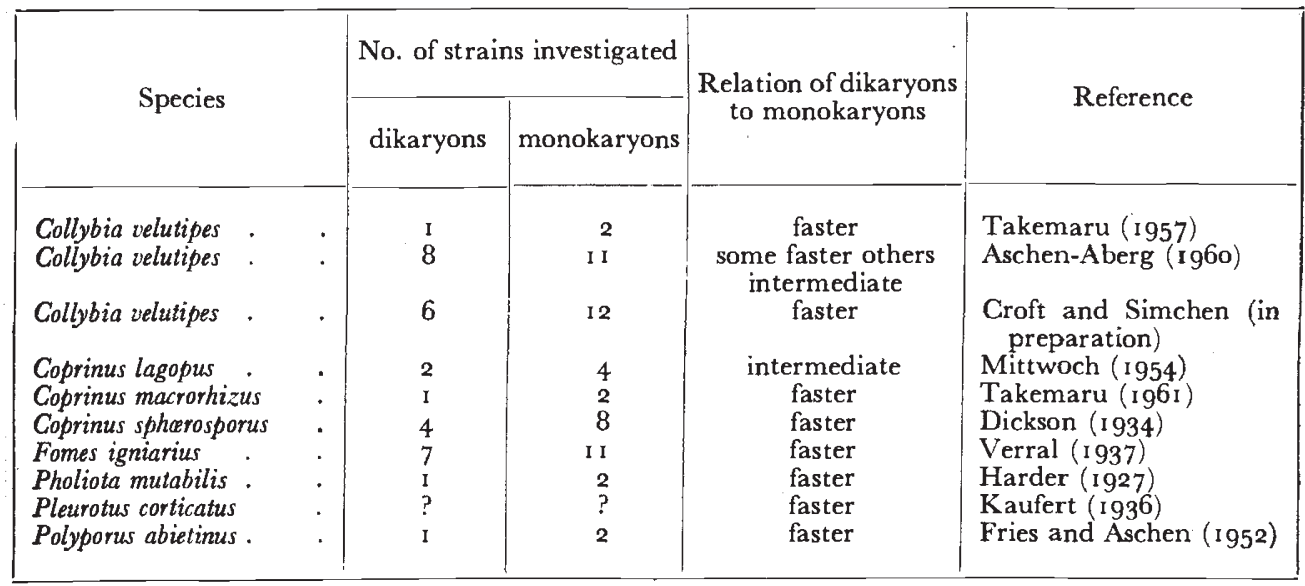

which the dikaryon is slower than the monokaryons. The relationship between growth rates of a dikaryon and its parental monokaryons depends therefore on the genotypic constitution of the component monokaryons, and not only on the dikaryotic state per se, just as does stability in development of heterozygotes (Jinks and Mather, 1955) which depends on the gene content and not on heterozygosity per se.

Another point of disagreement between some of the authors cited in table to is the correlation between the growth rates of a dikaryon and its parental monokaryons. Although none of these authors has carried out a statistical analysis of his data for the presence of such a correlation, they do discuss this correlation. Our results prove the existence of such a correlation, but also show that most of the genetic variation in growth rate of dikaryons is not correlated with variation in monokaryons, i.e. most genes which determine growth rate in dikaryons, either do not act in monokaryons or act in a different way. (Compare also $V_{\mathrm{M}}$, from table 8 , with $V_{\mathrm{P}}$, from table 6.) This conclusion is not surprising and indeed it is to be expected. Dikaryons and monokaryons 
differ considerably in the mechanism of elongation of hyphæ and cell division: while in a division of a dikaryotic cell both nuclei divide simultaneously and form a clamp-connection, the division of a monokaryotic cell is rather simple and does not require the formation of complicated structures like the clamps. The function and importance of both stages in the life cycle do not seem to be equal-growth of dikaryons must ultimately be the more important. The monokaryon is a temporary stage which comes to an end when two compatible monokaryons meet. On the other hand, a dikaryon which is able to grow faster and spread over a larger area, has the possibility of forming more fruiting bodies, providing of course it does not grow so fast that it exhausts all the food resources in the habitat. But competition between faster and slower growing dikaryons is not the whole story because monokaryons and dikaryons grow together in the same habitat and hence monokaryons presumably compete with dikaryons in their growth. The situation is further complicated by nuclear migration (Snider and Raper, 1958) and di-mon matings (Buller, I93 I).

\section{SUMMARY}

I. The determination of growth rate of dikaryons in the fungus Schizophyllum commune has been investigated by sets of crosses designed for biometrical analysis.

2. Estimates of the environmental, heritable additive and heritable non-additive components of variation have been obtained for two dikaryons recently collected in the wild, by analysing two sets of $6 \times 6$ crosses among the monokaryotic progeny of each dikaryon.

3. By calculating $W_{r}^{\prime} \mid V_{r}$ values, a genetic model which assumes additivity and dominance only has been shown to account for all the variation obtained. Thus dominance seems to be the only type of genetic interaction existing for the examined character. Dominance seems to be ambi-directional, suggesting that growth rate of dikaryons has been subjected to stabilising selection.

4. A regression analysis of the growth rates of dikaryons on their mid-parents monokaryotic growth rates provides an alternative method of estimating the components of variation for dikaryotic growth rate. Estimates are obtained of an heritable component which is correlated with growth rate of parental monokaryons, and of an heritable component which is not correlated. It is concluded that most variation in dikaryons is not correlated with variation in monokaryons, hence genes act in a different way in the monokaryotic and dikaryotic stages in the life cycle of Schizophyllum.

5. The relationship between the growth rate of a dikaryon and the growth rates of parental monokaryons depends on the genotypic constitutions of the two contributing parents. Most dikaryons grow faster than both parental monokaryons, others have an intermediate growth rate, and a few grow slower than either parental monokaryon. 
Acknowledgments.-We are indebted to Dr N. Montgomery and Dr J. Shack for collecting the material used in these investigations, to J. H. Groft for advice during both the investigations and the preparation of this paper, and to Prof. K. Mather, F.R.S., for advice on the presentation of the results.

\section{REFERENCES}

ASCHAN-ÅBERG, к. 196o. Studies on mono- and di-caryotic mycelia of Collybia velutipes. Physiol. Plant., 13, 280-297.

BREESE, E. L., AND MATHER, K. 196o. The organisation of polygenic activity within a chromosome in Drosophila. II. Viability. Heredity, 14, 375-399.

BULler, A. H. R. 1931. Researches on Fungi. IV. Longmans, Green, and Co., London.

COMSTOCK, R. E., AND ROBINSON, H. F. 1948. The components of genetic variance in populations of biparental progenies and their use in estimating the average degree of dominance. Biometrics, 4, 254-266.

COMSTOCK, R. E., AND ROBINSON, H. F. 1952. Estimation of average dominance of genes. In Heterosis, 494-5 I6. Iowa State College Press, Iowa.

CROFT, J. H., AND SIMCHEN, G. In preparation.

DICKson, H. 1934. Studies in Coprinus spharosporus. I. The pairing behaviour and the characteristics of various haploid and diploid strains. Ann. Bot., 48, 527-547.

FRIES, N., AND ASCHAN, K. 1952. The physiological heterogeneity of the dikaryotic mycelium of Polyporus abietinus investigated with the aid of micrurgical technique. Svensk Bot. Tidskr., 46, 429-445.

HARDER, R. 1927. Zur Frage nach der Rolle von Kern und Protoplasma im Zellgeschehen und bei der Übertragung von Eigenshaften. Zeitschr. f. Botanik, Ig, 335-407.

JiNks, J. L. 1954. The analysis of continuous variation in a diallel cross of Nicotiana rustica varieties. Genetics, 39, 767-788.

JINKS, J. L., AND MATHER, K. 1955. Stability in development of heterozygotes and homozygotes. Proc. Roy. Soc., B, I43, 561-578.

xaufert, F. H. 1936. The biology of Pleurotus corticatus Fries. Univ. Minn. Agric. Exp. St. Techn. Bull., II4.

MATHER, K. 1949. Biometrical Genetics. Methuen, London.

MATHER, K. 196o. Evolution in polygenic systems. In Evoluzione e Genetica, Accademia Nazionale dei Lincei. Qud., 47, I3I-I52.

мrтrwосн, $v$. 1954. The genetics of Coprinus lagopus. II. Growth rate of wild-type strains. 7. Genet., 52, 55 I-554.

RAPER, J. R. 1953. Tetrapolar sexuality. Quart. Rev. Biol., 28, 233-259.

RAPER, J. R., AND KRONGELB, G. S. 1958. Genetic and environmental aspects of fruiting in Schizophyllum commune Fr. Mycologia, 50, 707-740.

RAPER, J. R., AND MILES, P. G. 1958. The genetics of Schizophyllum commune. Genetics, 43, 530-546.

RYAN, F. J., BEADLE, G. W., AND TATUM, E. L. 1943. The tube method of measuring the growth rate of Neurospora. Amer. J. Bot., 30, 784-799.

SNIDER, P. J., AND RAPER, J. R. 1958. Nuclear migration in the basidiomycete Schizophyllum commune. Amer. F. Bot., 45, 538-546.

TAKEMARU, T. 1957. Genetics of Collybia velutipes. II. Growth rates of certain strains. Biol. 7. Okayama Univ., 3, 182-186.

TAKEMARU, T. $196 \mathrm{I}$. Genetical studies in fungi. X. The mating system in Humenomycetes and its genetical mechanism. Biol. F. Okayama Univ., 7, I33-2 I1.

verral, A. F. 1937. Variation in Fomes igniarius (L.). Gill. Univ. Minn. Agric. Exp. St. Tech. Bull., II7. 